\title{
Using participant hedonic ratings of food images to construct data driven food groupings ${ }^{\star}$
}

\author{
Susan L. Johnson ${ }^{\mathrm{a},{ }^{\star},}$, Richard E. Boles ${ }^{\mathrm{a}}$, and Kyle S. Burger ${ }^{\mathrm{b}}$ \\ aThe Department of Pediatrics, Section of Nutrition, University of Colorado-Denver Anschutz \\ Medical Campus, Aurora, CO, USA \\ bThe Department of Nutrition, University of North Carolina at Chapel Hill, Chapel Hill, NC, USA
}

\begin{abstract}
Theorists posit that food reward is a powerful determinant of intake, yet little is known regarding how individuals' hedonic ratings of a variety of foods interrelate and how hedonic ratings correspond to habitual dietary intake. Participant ratings of food appeal of 104 food images were collected while participants were in a fed state $(n=129)$. Self-reported frequency of intake of the food items, perceived hunger, body mass index (BMI), and dietary restraint were also assessed. Principal components analysis (PCA) was employed to analyze hedonic ratings of the foods, to identify component structures and to reduce the number of variables. The resulting component structures comprised 63 images loading on seven components including Energy-Dense Main Courses, Light Main Courses and Seafood as well as components more analogous to traditional food groups (e.g., Fruits, Grains, Desserts, Meats). However, vegetables were not represented in a unique, independent component. All components were positively correlated with reported intake of the food items ( $\mathrm{r}$ 's $=.26-.52, p<.05)$, except for the Light Main Course component $(\mathrm{r}=.10)$. BMI showed a small positive relation with aggregated food appeal ratings $(\mathrm{r}=.19 ; p<.05)$, which was largely driven by the relations between BMI and appeal ratings for Energy-Dense Main Courses $(\mathrm{r}=.24 ; p<.01)$ and Desserts $(\mathrm{r}=.27 ; p<.01)$. Dietary restraint showed a small significant negative relation to Energy-Dense Main Courses ( $\mathrm{r}=-.21 ; p<.05)$, and Meats $(\mathrm{r}=-$. $18 ; p<.05)$. The present investigation provides novel evidence that how individuals' hedonic ratings of foods aggregate into food components and how these component ratings relate to dietary intake. The notable absence of a vegetable component suggests that individuals' liking for vegetables is highly variable and, from an empirical standpoint, not related to how they respond hedonically to other food categories.
\end{abstract}

\section{Keywords}

Food and beverages; Food preferences; Vegetables; Obesity; Hedonic value

\footnotetext{
${ }^{\sqrt{3}}$ Support for this work was provided by the USDA Cooperative State Research, Education and Extension Service, grant number \# 2006-55215-16726. Additional funding support provided by the NIH (K23 DK087826) awarded to the second author.

(C) 2014 Elsevier Ltd. All rights reserved.

'Corresponding author: susan.johnson@ucdenver.edu (S.L. Johnson).
} 


\section{Introduction}

The hedonic value of food has been suggested to be a powerful determinant of dietary intake (Cabanac, 1985; Lowe \& Butryn, 2007; Mela, 2006). It has been suggested that hedonic influences can override the homeostatic mechanisms that control dietary intake and may play a role in weight regulation (Finlayson, King, \& Blundell, 2007a; Yeomans, Blundell, \& Leshem, 2004; Zheng \& Berthoud, 2007). Emerging data support the notion that overconsumption of energy-dense foods is associated with greater responsivity of brain reward circuitry during exposure to food cues in some individuals (Berridge, Ho, Richard, \& DiFeliceantonio, 2010; Burger \& Stice, 2011). For example, the hedonic value of food has been demonstrated to be predictive of energy consumption and/or the amount of food consumed at a meal (Drewnowski \& Hann, 1999) and is, via sensory specific properties, related to satiety (Hetherington \& Rolls, 1996). However, much remains to be elucidated regarding the perceived hedonic value of the wide variety of foods present in the current environment and how hedonic values relate to reported habitual dietary intake.

How individuals perceive relations among different foods has been studied from a number of perspectives including healthfulness, nutrient content, and cognitions about food and dietary intake (Chapman \& MacLean, 1993; Furst, Connors, Sobal, Bisogni, \& Falk, 2000; Worsley, 2002). Findings from studies that have assessed adult schemas related to food and eating have focused on both context and food groups (Blake, 2008; Blake, Bisogni, Sobal, Devine, \& Jastran, 2007). In one study using card-sorting protocols, participants were clustered into seven representations related to food and eating. The participants' schemas about foods were influenced predominantly by cognitions about mealtime and routines. In addition, factors related to convenience, meal components (e.g. main dish), well-being (e.g. health), person (e.g. food for husband or children), source (e.g. homemade), and food groups (as defined by investigators) were identified (Blake, 2008).

Nutrition education efforts have portrayed foods in well-defined food groups (e.g., grains, fruits, vegetables). The conceptualizations of food groups like those for the Food Guide Pyramid or MyPlate are largely based upon foods' biochemical properties (e.g. lipids), their source (e.g. plant/animal), and their effects on the body and relation to nutritional needs (U.S. Department of Agriculture National Nutrient Database for Standard Reference, 2014 accessed January 13, 2014). Conceived of by nutrition professionals in the early 20th century, these groupings have remained relatively unchanged, presumably in an effort to facilitate better understanding and acceptance by the consumer. However, less is known about whether consumers think about the relationship among foods; whether they think in terms of traditional food groups or whether they respond to other characteristics of the food, such as foods' hedonic values (e.g. liked vs. disliked foods), by energy density (e.g. energydense foods $v s$. low-energy foods), or other food characteristics (e.g. sweet $v s$. savory, or by color). In addition, responding to or categorizing foods may be particularly complex when foods include a mixture of the traditional food groups (e.g. casseroles, pizza, chef salads, burritos) and also may be influenced by individual-level differences. How individuals respond to and perceive food groupings is likely to be associated with physiological state, such as current weight status and hunger/fullness, as well as psychosocial characteristics 
such as self-reported dietary restraint (Ely, Winter, \& Lowe, 2013; Finlayson, King, \& Blundell, 2007b).

Obese individuals have differing responses (relative to their normal weight counterparts) to food stimuli including hedonic responses during lab-based taste preferences (Drewnowski \& Greenwood, 1983), behavioral food reinforcement tasks (Temple et al., 2009), and at the neural level during exposure to appetizing foods (Stice, Spoor, Bohon, Veldhuizen, \& Small, 2008; Stoeckel et al., 2008). Comparing overweight versus lean individuals' liking for foods with differing characteristics, and also comparing the interrelationships among ratings for various foods, has yet to be performed comprehensively.

Self-reported behaviors, such as dietary restraint, may also influence the perception of how foods relate to each other when based upon hedonic response. Dietary restraint, defined as intentional and sustained restriction of caloric intake for the purposes of weight loss or weight maintenance (Herman \& Mack, 1975), has an unclear relation with weight status. There is evidence that individuals with high dietary restraint scores are more reactive to food cues and have higher weight status (Laessle, Tuschl, Kotthaus, \& Pirke, 1989; Nederkoorn \& Jansen, 2001; Papies, Stroebe, \& Aarts, 2007; Roefs, Herman, MacLeod, Smulders, \& Jansen, 2005) and are at increased risk for future weight gain (Stice, Presnell, Groesz, \& Shaw, 2005; Tanofsky-Kraff, Haynos, Kotler, Yanovski, \& Yanovski, 2007). Individuals who differ in self-reported dietary restraint and dieting behaviors may also perceive the hedonic value of foods differently. However, few data are available regarding the relation between reported dietary restraint and perceived hedonic value of foods or whether dietary restraint influences interrelationships among hedonic responses to a variety of foods.

The primary goals of this study were to examine participants' hedonic ratings of foods: 1) to identify aggregates of foods from consumer hedonic ratings that are empirically based; 2) to compare these aggregates with food groups established by nutrition professionals (i.e. MyPyramid/MyPlate, U.S. Department of Agriculture ChooseMyPlate.gov, 2014 accessed April 13, 2014); and 3) to assess the relationships among hedonic ratings of data-driven food components, reported dietary intake, weight status, dietary restraint and perceived hunger.

\section{Materials \& methods}

\section{Participants}

A total of 130 individuals (Table 1) were enrolled in the present investigation, and, of those, $100(\mathrm{M}=42, \mathrm{~F}=58)$ completed a food frequency assessment. Hedonic ratings and food frequency data were initially collected on 100 participants for another study (Burger, Cornier, Ingebrigtsen, \& Johnson, 2011) that aimed to investigate the relations among food appeal, desire to eat and body weight status. An additional aim was added to the study to undertake a principal components analysis to understand how hedonic ratings might relate to food groupings. Feedback from the initial 100 participants suggested that the assessment was overly long, and thus the research team elected to remove the frequency questions for the additional sample $(n=30)$ to decrease participant burden, but achieve an appropriate sample size to perform principal component analysis. One female was excluded from analysis due to an outlying BMI (62.4). This participant's BMI was four SD above the mean 
and a Cook's Distance $>1$ revealed that the BMI was an overly influential data point. Of the total sample, $85 \%$ reported being White, $9 \%$ Black, 2\% Asian/Pacific Islander, and 1\%

Native American. Participants were recruited via flyers, email distribution lists and website message boards in the Denver Metro and Northern Colorado areas. Individuals were excluded if they reported having a visual disability that would affect the ability to differentiate colors, impaired night vision or any developmental impairment that could impact the ability to complete the measures. All procedures and measures were approved by the Colorado Multiple Institutional Review Board.

\section{ImageRate, Hedonic ratings and food frequency}

The computer program ImageRate was written in Microsoft Office Access ${ }^{\circledR}$ (Microsoft, Seattle, WA, 2007) and presented food images, one at a time, in a random order, and has previously been reported as a reliable instrument to assess hedonic ratings of food images (Burger et al., 2011). Hedonic ratings were assessed by a measure of food appeal which queried 'How appealing is this food?' anchored by $0=$ 'Not appealing at all' to $100=$ 'Extremely appealing.' An additional question was used to assess frequency of intake of each food in a subsample of participants. This question used a multiple choice format, similar to that of the widely established food frequency measures (e.g., Block et al., 1996), 'How often do you eat $\mathrm{X}$ (the name of the food presented)?' The seven response options ranged from, ' $1=$ Less than once in 3 months or never, $2=$ one to two times in 3 months, 3 $=$ Once per month, $4=$ two to three times a week, $5=$ two to four times a week, $6=$ five to seven times per week, 7 = Once a day or more.' All scales were presented under the image of each food, one at a time, on a 17 inch computer monitor in a quiet, dimly lit, private room where participants progressed at their own pace.

\section{Food images}

A total of 104 unique food images were presented. The foods depicted in the images were pretested to ensure that each was easily and consistently identified. A wide variety of foods (without overrepresentation of one kind of food item) was presented and in a state that was representative of typical consumption (i.e., prepared to eat). Images were selected to represent a variety of ethnic foods and foods for all eating occasions, such as snack, meal, individual foods and combinations. All images were matched for brightness and contrast using Microsoft Office Picture Manager ${ }^{\circledR}$ (Microsoft, 2007), sized to be at least $800 \times 600$ pixels, and were converted to a JPEG file type. No food logos or product advertisements were used to prevent confounding or influencing the rating of the food. Liquids were excluded from the image set due to difficulty in visually differentiating among different types of beverages. Additional detail regarding the development of the image set has been previously published (Burger et al., 2011).

\section{Dietary restraint}

The Three Factor Eating Questionnaire Restraint Scale (TFEQ; Stunkard \& Messick, 1985) is an 21 item scale that assesses dietary behaviors designed to produce weight loss or maintenance, monitoring of body shape, and importance of thinness (sample item: I count calories as a conscious means of controlling my weight). This scale has been demonstrated 
to have good internal consistency (a's range .85-.93) and temporal reliability (1-month testretest $r=.98$; French, Jeffery, \& Wing, 1994; Stunkard \& Messick, 1985).

\section{Procedures}

Participants attended one session conducted either at the University of Colorado Denver Anschutz Medical Campus or Colorado State University. Participants were scheduled such that they were able to adhere to their normal eating patterns the day prior to the session (not around a celebratory event) and the day of the session. Once informed consent was reviewed and obtained, participants were asked to consume $280 \%(\sim 190 \mathrm{~mL})$ of a liquid nutritional supplement ( $237 \mathrm{~mL} ; 240 \mathrm{kcal}, 10 \mathrm{~g}$ protein, $4 \mathrm{~g}$ fat; Nestlé HealthCare Nutrition, Fremont, MI 2008) to normalize participants' hunger levels across the sample. A gap of 15 min was placed between consumption of the nutritional drink and hedonic ratings to allow for the satiating effect of the supplement to occur. Following the $15 \mathrm{~min}$, participants were then asked to report their level of hunger by completing a Visual Analog Scale (VAS; 0-100; ranging from $0=$ 'not hungry' to $100=$ 'extremely hungry'). Once the hedonic ratings of the food images were completed, participants completed questionnaires and height (to the nearest $.1 \mathrm{~cm}$ ) and weight (to the nearest $.1 \mathrm{~kg}$ ) were measured twice with a wall-mounted stadiometer and a calibrated scale by trained research staff and then the two values were averaged.

\section{Statistical analyses}

Descriptive statistics were calculated (mean, SD) and distributions were examined for normality and linearity and found to be acceptable. To explore how participants' ratings of individual foods interrelated, exploratory factor analysis was performed utilizing principal components analysis (PCA) on the 104 food images. Data utilized for the PCA procedures were structured by creating a matrix of 104 food image columns by participant rows. Each cell represented an individual's VAS rating for that specific food image. The purpose of PCA for this study was to reduce the number of variables into summarized correlation patterns (i.e., components). Ratings of food items in response to food appeal were first tested for PCA suitability based on the determinant of the R-matrix (>.00001; Field, 2005), commonalities after extraction (>.5; Field, 2005), KMO (>.5; Kaiser, 1974), and Bartlett's test of sphericity (significant Chi-square test; Field, 2005). Items were removed upon inspection for cross-loaded items (more than .35 on multiple scales) or with low factor loadings (i.e., <.40; Bryant \& Yarnold, 1995) or highly correlated items (greater than .8, Field, 2005). Varimax rotation was used to increase interpretability by minimizing low correlations and maximizing high correlations. The number of retained components were based on screen plot examinations and eigenvalues greater than 1.0 (Kaiser, 1974). IBM SPSS Statistics 20 (SPSS inc., Chicago, IL, USA) was used for all study analyses.

After the PCA analysis was conducted for images based on food appeal ratings and the component structures were determined, internal consistency was assessed and the authors viewed the images by each component and independently named the components based on common characteristics of the images represented in each of the components. The names were then collectively reviewed until component names were agreed upon. Mean hedonic ratings of appeal and mean frequency of intake were calculated for overall rating and for 
each food component. These mean component ratings were then used in correlation and regression analyses examining the relations between BMI, ratings, and intake. To assess the degree to which components based on hedonic ratings dovetailed with those in the basic nutrition food groups, we assessed for percent agreement of images within each PCA component to a priori groups based on the traditional food groups and a mixed dishes group (i.e. containing a mixture of foods with no dominant individual food) as reported in a previous study (Burger et al., 2011).

\section{Results}

\section{Principal component analysis (PCA)}

The correlation matrices of food items for food appeal were first examined for near perfect correlation $(r>.90)$, resulting in the elimination of one item. All communalities after extraction were above .5 as suggested by Field (2005). The Kaiser-Meyer-Olkin measure of sampling adequacy $(>.50)$ and Bartlett's test of sphericity $(p<.05)$ were both acceptable, suggesting adequate data for structure detection. Food appeal's component structure was comprised of 63 items across seven components accounting for $44.3 \%$ of the total variance (Table 2). The internal consistency coefficient was strong for food appeal ( $a$ 's ranging from .82 to .93). Table 3 presents the component structures, names, internal consistency, mean hedonic ratings, frequency of consumption and sample items. Components names include: Energy dense Main Courses, Fruits, Meats, Desserts, Light Main Courses, Seafood, and Grains.

\section{Percent agreement with a priori, traditional food groups}

Percent agreement was $100 \%$ for the PCA components that mapped to three traditional food groups (Fruit, Meats, and Grains; Table 4), indicating that components based on hedonic ratings fall directly in line with traditional food groups. Five of the seven images presented in Seafood component were represented in the a priori Protein Food group. Desserts showed strong agreement with the traditional Discretionary Foods group ( $8 / 9$ items), whereas Energy-Dense and Light Main Courses showed the poorest agreement, 47\% and 57\% respectively. The low agreement in the energy dense dishes is understandable given that the images included more complex mixtures of foods and thus, it was not surprising that variability in hedonic ratings would be higher. Hedonic ratings of vegetables did not result in a discernable component from the PCA and therefore no percent agreement with this food group could be calculated.

\section{Frequency of intake and hedonic ratings $(n=99)$}

Reported dietary intake (Table 3 ), was positively correlated with hedonic ratings for EnergyDense Main Courses $(\mathrm{r}=.56 ; p<.001)$, Desserts $(\mathrm{r}=.33 ; p=.001)$, Fruits $(\mathrm{r}=.26 ; p=.01)$, Grains $(\mathrm{r}=.43 ; p<.001)$, Seafood $(\mathrm{r}=.52 ; p<.001)$, and Meats $(\mathrm{r}=.51 ; p<.001)$. However, intake was not significantly related to appeal ratings of the Light Main Courses components $(\mathrm{r}=.10, p=.33)$, which contained the most prominent depiction of vegetables.

In exploratory analyses, we observed a similar pattern of correlations between hedonic ratings and dietary intake when separating lean $(\mathrm{BMI}<24.9 ; \mathrm{n}=59)$ and overweight (BMI 
$>25 ; \mathrm{n}=40$ ) individuals. Lean individuals showed a significant relation between appeal ratings and intake of Fruit (lean: $\mathrm{r}=.35 ; p<.01$; overweight: $\mathrm{r}=.15 ; p=.34$ ) and a lower relation between appeal and intake of Desserts (lean: $\mathrm{r}=.29 ; p=.02$; overweight: $\mathrm{r}=.42 ; p$ $<.001)$. These differences were not statistically different, however, using Fisher's r-to-z transformations ( $p=.12$ and $p=.20$, respectively).

\section{Hedonic ratings, BMI, dietary restraint, perceived hunger and frequency of intake}

BMI showed a small positive relation with aggregated appeal ratings $(\mathrm{r}=.19 ; p<.05)$ suggesting that individuals with a higher BMI rate foods overall as more appealing. This effect was primarily driven by the relation between BMI and appeal ratings for EnergyDense Main Courses $(\mathrm{r}=.24 ; p<.01)$ and Desserts $(\mathrm{r}=.27 ; p<.01)$. However, overall, BMI was not significantly related to intake of any food component (see Table 5).

Participants' dietary restraint scores in this sample were comparable with scores for the restraint scale of the TFEQ reported in other recent studies (Waugh, Polivy, Ridout, \& Hawker, 2007; Williamson et al., 2007). Dietary restraint was not significantly related to aggregate appeal ratings $(\mathrm{r}=-.12 ; p=.18)$ but was negatively related to appeal ratings for Energy-Dense Main Courses ( $\mathrm{r}=-.21 ; p<.05)$, and Meats $(\mathrm{r}=-.18 ; p<.05)$. Dietary restraint scores were negatively associated with intake of Energy-dense Main Courses $(p<$. $05)$ and Meats $(p<.05)$.

Despite participants being in a fed state, hunger was positively correlated with aggregated ratings $(\mathrm{r}=.19 ; p<.05)$. Hunger was positively correlated with appeal ratings specifically for Energy-Dense Main Courses ( $\mathrm{r}=.34 ; p<.001)$, Meats $(\mathrm{r}=.25 ; p<.01)$, and Seafood ( $\mathrm{r}$ $=.22 ; p<.05)$ and with frequency of intake of Energy-Dense Main Courses $(p<.01)$ and Meats $(p<.05$; Table 5).

\section{Discussion}

Reliable component structures of hedonic ratings of food images were identified based on preliminary instrument validation. Some level of consistency was noted between traditional food groups and the components derived from hedonic ratings. Most notably, Fruits and Grains had perfect agreement between the two systems. However, participants' ratings resulted in four components for Protein Foods: Energy-Dense Main Courses, Meats, Light Main Courses and Seafood, suggesting that participants respond to these kinds of Protein Foods at a more granular level than traditional groupings allow. We were unable to locate any other published literature related to food components based upon consumer liking (for more than one category of food) or data-derived methods, but our findings indicate some finer grain distinctions in how individuals respond to different foods, particularly foods that serve as a "main course." Interestingly, a reliable, singular component for vegetables did not emerge, which may signify that preferences for vegetables are highly variable across participants, very specific within participants and/or unconnected to how they perceive other foods. In a previous report of participant ratings of all 15 items that represented vegetables in the original ImageRate set, liking for vegetables was low with considerable variability (56.2 \pm 13.2 ; Burger et al., 2011). It should be noted that reported frequency of intake of the items might have been low and this may be due to the specificity of looking at an image of a 
food item (e.g. a green apple) as opposed to being asked about the frequency of consumption of a food (e.g. "how often do you consume apples?").

Hedonic ratings were positively related to reported intake of the foods depicted in all components, except for intake of Light Main Courses (that included some vegetables in mixed dishes). In general, a higher rating for a component's food appeal was associated with a higher reported frequency of consumption. The strongest associations between hedonic ratings and consumption were for foods high in energy density, aligning well with population-based studies that have reported that high calorie foods are most preferred (Gibson \& Wardle, 2003). Previous experimental work in laboratory animals and in children has further confirmed that foods of high energy content become preferred over those that have fewer calories (Johnson, McPhee, \& Birch, 1991; Kern, McPhee, Fisher, Johnson, \& Birch, 1993; Sclafani, 2001).

Energy state also seemed to play a role in participants' perceived liking for the various food components. Participants in this study rated food images while in a relatively fed state and, overall, expressed highest ratings for lower energy and sweet foods. That said, perceived hunger varied across participants and the participants' hunger was also positively associated with ratings for foods that were more energy dense. These findings are consistent with research that suggests food preferences differ in the fed and fasted states such that foods higher in energy density are more preferred when subjects are hungry (Berthoud, 2011; Mehta et al., 2012).

We observed small, but statistically significant, associations between participant characteristics, such as dietary restraint and BMI, and hedonic ratings of food components. Individuals' BMIs were positively associated with ratings for Energy-Dense Main Courses and Desserts while a significant correlation between appeal ratings and intake of Fruit was noted for lean individuals. Individuals with higher BMIs who rated the higher energy densities foods as appealing would suggest that these individuals may also consume higher energy foods that result in higher energy intake. However, this was not supported by the data related to frequency of consumption. It may be that individuals with higher BMIs do not consume energy dense foods more often, but do so episodically and in larger amounts. In contrast, dietary restraint was negatively associated with appeal ratings for Meats and Energy-Dense Main Courses and, since these items are likely to be higher in fat and energy, may ideationally be less preferred by restrained individuals (Hoefling \& Strack, 2008; Tepper, Choi, \& Nayga, 1997).

Restrained eaters have conflicting reactions to high energy foods (Stroebe, Mensink, Aarts, Schut, \& Kruglanski, 2008). They may seek to avoid high energy foods to control weight but many individuals have occasions where they indulge in these foods and therefore are not consistently successful in shunning them (Hofmann, van Koningsbruggen, Stroebe, Ramanathan, \& Aarts, 2010). The foods that trigger these lapses are considered to be highly palatable foods and the sight and smell of such foods evokes strong responses in at least some restrained eaters (Fedoroff, Polivy, \& Herman, 1997; Houben, Roefs, \& Jansen, 2010; Jansen \& van den Hout, 1991). The literature is conflicted regarding whether hedonic or attitudinal responses for high and low calorie (fat) foods differ by participants' restraint 
characteristics. In a study comparing responses of restrained and unrestrained eaters, all participants (irrespective of dietary restraint scores) evaluated "palatable foods" as being more positive than "unpalatable foods" (Roefs et al., 2005). Some previous investigations have not noted significant associations among dietary restraint, food preference and dietary intake (Drewnowski \& Hann, 1999; Oliver, Wardle, \& Gibson, 2000) while other smaller studies have reported avoidance of dietary fat by restrained individuals (Tuschl, Laessle, Platte, \& Pirke, 1990).

We report that individuals scoring higher on restraint gave lower hedonic ratings to high energy, high fat, savory foods and no associations of restraint scores with sweet or low energy foods. Some of the disagreement between ours and other studies' findings could be attributed to the kinds of foods that have been included in different protocols. The foods most often assessed in other protocols have been high in fat and sugar or were energy dense snack foods (Bowen et al., 2003; Houben et al., 2010; Roefs \& Jansen, 2004; Tuorila, Meiselman, Cardello, \& Lesher, 1998; Westcombe \& Wardle, 1997). Our study protocol asked participants to rate high and low energy foods, sweet and savory foods and then looked for associations with participants' restraint scores. We noted no associations between ratings of desserts and fruits (sweet foods) and dietary restraint, but all participants rated these foods as high in appeal (Table 2).

Another methodological difference between ours and other studies is that we elected to have participants rate food images after having consumed a controlled snack (that was sweet tasting). The mean scores for perceived hunger, while variable, were on the lower end of the range and therefore most participants were not particularly hungry when completing the rating task. The low hunger state likely relates to participants' mean ratings of the various food components. Energy dense main courses, meats, seafood and grains were among the lowest ranked components which is consistent with other studies that have reported that energy state influences levels of neuronal activation (Cornier, Von Kaenel, Bessesen, \& Tregellas, 2007) and food evaluations (Hoefling \& Strack, 2008). In most studies that focus on dietary restraint and hedonic ratings, participants' energy state was not reported to be controlled or measured.

Further work is needed to determine whether hedonic ratings of foods consistently predict individual differences such as dietary restraint, food selection, energy intake and BMI and whether hedonic ratings can predict future weight gain. Additionally, insights into potential differences in associations between hedonic ratings and dietary intake could be gained by contrasting empirically derived food components (like those used in this study) with methods in which participants group foods according to their appeal (Nguyen, 2007).

Participant ratings of images of vegetables did not load onto a unique component, though several of the mixed vegetable dishes and salads fell into the Light Main Courses component. Because vegetables frequently can taste bitter and are low in energy (and people generally report low preferences for them), this may account for their absence from components that are based upon ratings for food appeal. One study that investigated the relation between energy density and preferences for fruits and vegetables reported that children's preference increased as energy density increased, accounting for $42 \%$ of the 
variability in children's liking for fruits and vegetables (Gibson \& Wardle, 2003). In a subsequent study by the same group, vegetables were the lowest ranked food group and fatty/sugary foods were highest, again supporting that energy density is related to hedonic ratings (Cooke \& Wardle, 2005).

A better understanding of the temporal nature of the relation between hedonic value (i.e. food appeal) and habitual intake may provide insight as to why singular vegetables did not emerge as a component. Specifically, it is unclear whether initial positive hedonic responses to foods drive future intake, as presented in some models (Davis, Strachan, \& Berkson, 2004), and/or whether the act of habitually consuming a food (perhaps to the point of monotony) results in changes in cue susceptibility and/or food preference that then drive intake (Berridge et al., 2010; Burger \& Stice, 2011; Zandstra, de Graaf, \& Van Trijp, 2000). This is a particularly interesting question in the context of vegetable acceptance and consumption, as vegetables can initially be rejected, but acceptance can occur after repeated exposure (Birch, 1999; Johnson, Bellows, Beckstrom, \& Anderson, 2007; Wardle, Herrera, Cooke, \& Gibson, 2003). Expected liking or acceptance of unfamiliar foods has been linked with how the unfamiliar food relates to familiar or referent foods that are regularly consumed by the individual (Tuorila et al., 1998). It is plausible to suggest that if vegetables were being consumed more often, then more would be considered familiar and would emerge in an aggregate component, and appeal ratings might be more likely to emerge as a factor. The average reported intake of foods represented by images of single vegetables (i.e. five images depicted a single type of vegetable) was less than one time per month, giving credence to the notion that the vegetables in our image set were not eaten often.

It is important to acknowledge the limitations of the present investigation. First, it is unclear whether food appeal ratings are a predictor of objectively measured taste preferences and dietary intake. It could also be argued that the images of foods selected for the ImageRate program were unrepresentative of participants' usual food choices. If this were the case, this could have affected their hedonic ratings, and therefore had an influence on the construction of the food components based upon the principal components analyses. The frequency of reported intakes ranged across all seven response categories ('Less than once in three months' to 'Twice or more per day), which argues against this particular bias in the data.

Another potential limitation is that we chose to control participant hunger in the present study by having all participants consume the same volume of a nutritional beverage. While the volume and energy consumed was consistent, energy needs likely varied across participants. Thus, variance was introduced in the extent to which the beverage induced satiety across participants. Since ratings were not assessed in a fasted state, limited inferences can be made regarding impact of energy state on hedonic ratings, though previous studies indicate differential hedonic ratings based on physiological hunger state during assessment (Finlayson, King, \& Blundell, 2008). Additionally, self-reported dietary intake has been shown to have systematic biases based on weight of the reporter in some samples (Lissner et al., 2007) and therefore reporting of frequency of food intake may not have been accurate. Finally, the instrument used to elicit hedonic ratings will benefit from additional psychometric testing, including confirmatory factor analysis to support our structure identified via PCA. 
Strengths of the current study include the recruitment of a sample that included adult males and females of varying weight status and dietary restraint characteristics. Moreover, the method of ascertaining food appeal via response to food images at least partially circumvents issues of previous investigations that have required participants to form a mental representation associated with the word for a particular food in order to answer the questions (Drewnowski \& Hann, 1999). Using photos standardizes participant responses in that each respondent has the same visual image of the food that they are rating and for which they are reporting frequency of consumption. Evaluation of the hedonic ratings via PCA allows for the empirically driven construction of participant food components, rather than imposing the expectation that liking for foods is best analyzed according to traditional nutrition-based groups.

\section{Conclusions}

The present investigation provides novel evidence that perceived hedonic ratings provide novel insights into how individuals respond to individual foods and aggregates of foods. Food ratings are influenced by sensory and nutrient properties of food, but also may be influenced by other characteristics such as level of dietary restraint, energy state, weight status, frequency of intake and knowledge of health, food and traditional food groupings (Drewnowski \& Hann, 1999; Stein et al., 2013). In this study, food components created according to perceived appeal resulted in some components that held similarities to traditional food groups and some nuances in how individuals respond to "main courses," typically thought to be captured in the Protein Foods category. That appeal ratings fell into four categories (Light Main Courses, Energy-Dense Main Courses, Seafood and Meats) may relate to untapped eating beliefs and behaviors, such as vegetarianism or food exclusions for health. A notable exception was the identification of a component comprised exclusively of vegetables. Vegetables are a food group that the majority of Americans are not consuming at a level that meets recommendations (Blanck, Gillespie, Kimmons, Seymour, \& Serdula, 2008) and for which intervention effects are equivocal (Alexander et al., 2010; Hoffman et al., 2011; Stadler, Oettingen, \& Gollwitzer, 2010; Thomson \& Ravia, 2011). Our data suggest that preferences for vegetables are sufficiently low or variable to a point that recommendations to increase consumption, like those in the Dietary Guidelines for Americans (U.S. Department of Agriculture and U.S. Department of Health and Human Services, 2010), are likely to be unsuccessful. If individuals do not respond to these foods in a way that results in a recognizable component, then increasing their consumption seems doubtful. A better understanding of the interactions among food characteristics, experience, availability, hedonic value/reward, and habitual intake may provide insight into the perpetually low vegetable intake in the United States and other developed countries and provide a foundation for more effective healthy eating interventions.

\section{Uncited reference}

Birch LL, McPhee L, Shoba BC, Pirok E, Steinberg L. What kind of exposure reduces children's food neophobia? Looking vs. tasting. Appetite. 1987; 9(3):171-178. [PubMed: 3435134] 


\section{References}

Alexander GL, McClure JB, Calvi JH, Divine GW, Stopponi MA, Rolnick SJ, et al. A randomized clinical trial evaluating online interventions to improve fruit and vegetable consumption. American Journal of Public Health. 2010; 100(2):319-326. [PubMed: 20019315]

Berridge KC, Ho CY, Richard JM, DiFeliceantonio AG. The tempted brain eats. Pleasure and desire circuits in obesity and eating disorders. Brain Research. 2010; 1350:43-64. [PubMed: 20388498]

Berthoud HR. Metabolic and hedonic drives in the neural control of appetite. Who is the boss? Current Opinion in Neurobiology. 2011; 21(6):888-896. [PubMed: 21981809]

Birch LL. Development of food preferences. Annual Review of Nutrition. 1999; 19(1):41-62.

Blake CE. Individual differences in the conceptualization of food across eating contexts. Food Quality and Preference. 2008; 19:62-70. [PubMed: 19122739]

Blake CE, Bisogni CA, Sobal J, Devine CM, Jastran M. Classifying foods in contexts. How adults categorize foods for different eating settings. Appetite. 2007; 49:500-510. [PubMed: 17512088]

Blanck HM, Gillespie C, Kimmons JE, Seymour JD, Serdula MK. Trends in fruit and vegetable consumption among US men and women, 1994-2005. Preventing Chronic Disease. 2008; 5(2) <http://www.cdc.gov/pcd/issues/2008/apr/07_0049.htm.

Block G, Hartman AM, Dresser CM, Carroll MD, Gannon J, Gardner L. A data-based approach to diet questionnaire design and testing. American Journal of Epidemiology. 1996; 124:453-469. [PubMed: 3740045]

Bowen D, Green P, Vizenor N, Vu C, Kreuter P, Rolls B. Effects of fat content on fat hedonics. Cognition or taste. Physiology and Behavior. 2003; 78:247-253. [PubMed: 12576122]

Bryant, FB.; Yarnold, PR. Principal-components analysis and confirmatory factor analysis. In: Grimm, LG.; Yarnold, PR., editors. Reading and understanding multivariate statistics. Washington, DC: American Psychological Association; 1995. p. 99-136.

Burger KS, Cornier MA, Ingebrigtsen J, Johnson SL. Assessing food appeal and desire to eat. The effects of portion size \& energy density. The International Journal of Behavioral Nutrition and Physical Activity. 2011; 8(1):101. [PubMed: 21943082]

Burger KS, Stice E. Variability in reward responsivity and obesity. Evidence from brain imaging studies. Current Drug Abuse Reviews. 2011; 4(3):182. [PubMed: 21999692]

Cabanac M. Preferring for pleasure. The American Journal of Clinical Nutrition. 1985; 42(5):11511155. [PubMed: 4061361]

Chapman G, MacLean H. 'Junk food' and 'healthy food'. Meanings of food in adolescent women's culture. Journal of Nutrition Education. 1993; 25:108-113.

Cooke LJ, Wardle J. Age and gender differences in children's food preferences. The British Journal of Nutrition. 2005; 93(5):741-746. [PubMed: 15975175]

Cornier MA, Von Kaenel SS, Bessesen DH, Tregellas JR. Effects of overfeeding on the neuronal response to visual food cues. The American Journal of Clinical Nutrition. 2007; 86(4):965-971. [PubMed: 17921372]

Davis C, Strachan S, Berkson M. Sensitivity to reward. Implications for overeating and overweight. Appetite. 2004; 42:131-138. [PubMed: 15010176]

Drewnowski A, Greenwood MRC. Cream and sugar. Human preferences for high-fat foods. Physiology \& Behavior. 1983; 30(4):629-633. [PubMed: 6878464]

Drewnowski A, Hann C. Food preferences and reported frequencies of food consumption as predictors of current diet in young women. The American Journal of Clinical Nutrition. 1999; 70(1):28-36. [PubMed: 10393135]

Ely AV, Winter S, Lowe MR. The generation and inhibition of hedonically-driven food intake. Behavioral and neurophysiological determinants in healthy weight individuals. Physiology \& Behavior. 2013; 121:25-34. [PubMed: 23562869]

Fedoroff IC, Polivy J, Herman CP. The effect of pre-exposure to food cues on the eating behaviour of restrained and unrestrained eaters. Appetite. 1997; 28:33-47. [PubMed: 9134093]

Field, A. Discovering statistics using SPSS. 2. London: SAGE; 2005. 
Finlayson G, King N, Blundell J. The role of implicit wanting in relation to explicit liking and wanting for food. Implications for appetite control. Appetite. 2008; 50(1):120-127. [PubMed: 17655972]

Finlayson G, King N, Blundell JE. Liking vs. wanting food. Importance for human appetite control and weight regulation. Neuroscience and Biobehavioral Reviews. 2007a; 31(7):987-1002. [PubMed: 17559933]

Finlayson G, King N, Blundell JE. Is it possible to dissociate 'liking' and 'wanting' for foods in humans? A novel experimental procedure. Physiology \& Behavior. 2007b; 90(1):36-42. [PubMed: 17052736]

French SA, Jeffery RW, Wing RR. Food intake and physical activity. A comparison of three measures of dieting. Addictive Behaviors. 1994; 19(4):401-409. [PubMed: 7992675]

Furst TM, Connors M, Sobal J, Bisogni CA, Falk LW. Food classifications. Levels and categories. Ecology of Food and Nutrition. 2000; 39:331-355.

Gibson EL, Wardle J. Energy density predicts preferences for fruit and vegetables in 4-year-old children. Appetite. 2003; 41(1):97-98. [PubMed: 12880626]

Herman CP, Mack D. Restrained and unrestrained eating. Journal of Personality. 1975; 43:647-660. [PubMed: 1206453]

Hetherington, MM.; Rolls, BJ. Sensory-specific satiety. Theoretical frameworks and central characteristics. In: Capaldi, ED., editor. Why we eat what we eat. The psychology of eating. Washington, DC, USA: American Psychological Association; 1996. p. 267-290.

Hoefling A, Strack F. The tempting effect of forbidden foods. High calorie content evokes conflicting implicit and explicit evaluations in restrained eaters. Appetite. 2008; 51:681-689. [PubMed: 18619504]

Hoffman JA, Thompson DR, Franko DL, Power TJ, Leff SS, Stallings VA. Decaying behavioral effects in a randomized, multi-year fruit and vegetable intake intervention. Preventive Medicine. 2011; 52(5):370-375. [PubMed: 21371499]

Hofmann W, van Koningsbruggen GM, Stroebe W, Ramanathan S, Aarts H. As pleasure unfolds. Hedonic responses to tempting food. Psychological Science. 2010; 21(12):1863-1870. [PubMed: 21106885]

Houben K, Roefs A, Jansen A. Guilty pleasures. Implicit preferences for high calorie food in restrained eating. Appetite. 2010; 55(1):18-24. [PubMed: 20211211]

Jansen A, van den Hout MA. On being led into temptation. "Counter-regulation" of dieters after smelling a "preload". Addictive Behaviors. 1991; 16:247-253. [PubMed: 1776541]

Johnson SL, Bellows L, Beckstrom L, Anderson J. Evaluation of a social marketing campaign targeting preschool children. American Journal of Health Behavior. 2007; 31(1):44-55. [PubMed: 17181461]

Johnson SL, McPhee L, Birch LL. Conditioned preferences. Young children prefer flavors associated with high dietary fat. Physiology \& Behavior. 1991; 50(6):1245-1251. [PubMed: 1798782]

Kaiser HF. An index of factorial simplicity. Psycho. 1974; 39:31-36.

Kern DL, McPhee L, Fisher J, Johnson S, Birch LL. The postingestive consequences of fat condition preferences for flavors associated with high dietary fat. Physiology \& Behavior. 1993; 54(1):7176. [PubMed: 8327611]

Laessle RG, Tuschl RJ, Kotthaus BC, Pirke KM. A comparison of the validity of three scales for the assessment of dietary restraint. Journal of Abnormal Psychology. 1989; 98(4):504. [PubMed: 2592686]

Lissner L, Troiano RP, Midthune D, Heitmann BL, Kipnis V, Subar AF, et al. OPEN about obesity. Recovery biomarkers, dietary reporting errors and BMI. International Journal of Obesity. 2007; 31(6):956-961. [PubMed: 17299385]

Lowe MR, Butryn ML. Hedonic hunger. A new dimension of appetite? Physiology \& Behavior. 2007; 91(4):432-439. [PubMed: 17531274]

Mehta S, Melhorn SJ, Smeraglio A, Tyagi V, Grabowski T, Schwartz MW, et al. Regional brain response to visual food cues is a marker of satiety that predicts food choice. The American Journal of Clinical Nutrition. 2012; 96(5):989-999. [PubMed: 22990034]

Mela DJ. Eating for pleasure or just wanting to eat? Reconsidering sensory hedonic responses as a driver of obesity. Appetite. 2006; 47(1):10-17. [PubMed: 16647788] 
Nederkoorn C, Jansen A. Cue reactivity and eating behavior. Journal of Psychophysiology. 2001; 15(3):216.

Oliver G, Wardle J, Gibson EL. Stress and food choice. A laboratory study. Psychosomatic Medicine. 2000; 62(6):853-865. [PubMed: 11139006]

Papies EK, Stroebe W, Aarts H. Pleasure in the mind. Restrained eating and spontaneous hedonic thoughts about food. Journal of Personality and Social Psychology. 2007; 81:181-192.

Roefs A, Herman CP, MacLeod CM, Smulders FTY, Jansen A. At first sight. How do restrained eaters evaluate high-fat palatable foods? Appetite. 2005; 44(1):103-114. [PubMed: 15604037]

Roefs A, Jansen A. The effect of information about fat content on food consumption in overweight/ obese and lean people. Appetite. 2004; 43:319-322. [PubMed: 15527936]

Sclafani A. Psychobiology of food preferences. International Journal of Obesity and Related Metabolic Disorders: Journal of the International Association for the Study of Obesity. 2001; 25:S13-S16.

Stadler G, Oettingen G, Gollwitzer PM. Intervention effects of information and self-regulation on eating fruits and vegetables over two years. Health Psychology. 2010; 29(3):274-283. [PubMed: 20496981]

Stein, S.; Lamos, E.; Quartuccio, M.; Chandraskaran, S.; Ionica, N.; Steinle, N. Diet quality. New York: Springer; 2013. Food intake and food preference; p. 13-25.

Stice E, Presnell K, Groesz L, Shaw H. Effects of a weight maintenance diet on bulimic symptoms in adolescent girls. An experimental test of the dietary restraint theory. Health Psychology. 2005; 24(4):402. [PubMed: 16045376]

Stice E, Spoor S, Bohon C, Veldhuizen MG, Small DM. Relation of reward from food intake and anticipated food intake to obesity. A functional magnetic resonance imaging study. Journal of Abnormal Psychology. 2008; 117(4):924. [PubMed: 19025237]

Stoeckel LE, Weller RE, Cook EW III, Twieg DB, Knowlton RC, Cox JE. Widespread reward-system activation in obese women in response to pictures of high-calorie foods. Neuroimage. 2008; 41(2): 636-647. [PubMed: 18413289]

Stroebe W, Mensink W, Aarts H, Schut H, Kruglanski AW. Why dieters fail. Testing the goal conflict model of eating. Journal of Experimental Social Psychology. 2008; 44:26-36.

Stunkard A, Messick S. The three factor eating questionnaire to measure dietary restraint, disinhibition, and hunger. Journal of Psychosomatic Research. 1985; 29(1):71-83. [PubMed: 3981480]

Tanofsky-Kraff M, Haynos AF, Kotler LA, Yanovski SZ, Yanovski JA. Laboratory-based studies of eating among children and adolescents. Current Nutrition and Food Science. 2007; 3(1):55-74. [PubMed: 19030122]

Temple JL, Bulkley AM, Badawy RL, Krause N, McCann S, Epstein LH. Differential effects of daily snack food intake on the reinforcing value of food in obese and nonobese women. The American Journal of Clinical Nutrition. 2009; 90(2):304-313. [PubMed: 19458018]

Tepper BJ, Choi YS, Nayga RM. Understanding food choice in adult men. Influence of nutrition knowledge, food beliefs and dietary restraint. Food Quality and Preference. 1997; 8(4):307-317.

Thomson CA, Ravia J. A systematic review of behavioral interventions to promote intake of fruit and vegetables. Journal of the American Dietetic Association. 2011; 111(10):1523-1535. [PubMed: 21963019]

Tuorila HM, Meiselman HL, Cardello AV, Lesher LL. Effect of expectations and the definition of product category on the acceptance of unfamiliar foods. Food Quality and Preference. 1998; 9(6): 421-430.

Tuschl RJ, Laessle RG, Platte P, Pirke KM. Differences in food-choice frequencies between restrained and unrestrained eaters. Appetite. 1990; 14(1):9-13. [PubMed: 2310178]

U.S. Department of Agriculture and U.S. Department of Health and Human Services. Dietary Guidelines for Americans, 2010. 7. Washington, DC: U.S. Government Printing Office; 2010.

U.S. Department of Agriculture ChooseMyPlate.gov. [Last accessed 13.01.14.] Retrieved from the ChooseMyPlate.gov website. 2014. <http://www.choosemyplate.gov/food-groups/>

U.S. Department of Agriculture National Nutrient Database for Standard Reference. [Last accessed 13.01.14.] Retrieved from Nutrient Data Laboratory website Home Page. 2014. <http:// www.ars.usda.gov/ba/bhnrc/ndl> 
Wardle J, Herrera ML, Cooke L, Gibson EL. Modifying children's food preferences. The effects of exposure and reward on acceptance of an unfamiliar vegetable. European Journal of Clinical Nutrition. 2003; 57(2):341-348. [PubMed: 12571670]

Waugh EJ, Polivy J, Ridout R, Hawker GA. A prospective investigation of the relations among cognitive dietary restraint, subclinical ovulatory disturbances, physical activity, and bone mass in healthy young women. The American Journal of Clinical Nutrition. 2007; 86:1791-1801. [PubMed: 18065600]

Westcombe A, Wardle J. Influence of relative fat content information on responses to three foods. Appetite. 1997; 28:49-62. [PubMed: 9134094]

Williamson DA, Martin CK, York-Crowe E, Anton SD, Redman LM, Han H, et al. Measurement of dietary restraint. Validity tests of four questionnaires. Appetite. 2007; 48(2):183-192. [PubMed: 17101191]

Worsley A. Nutrition knowledge and food consumption. Can nutrition knowledge change food behavior? Asia Pacific Journal of Clinical Nutrition. 2002; 11:S579-S585. [PubMed: 12492651]

Yeomans MR, Blundell JE, Leshem M. Palatability. Response to nutritional need or need-free stimulation of appetite? The British Journal of Nutrition. 2004; 92(S1):S3-S14. [PubMed: 15384315]

Zandstra EH, de Graaf C, Van Trijp HCM. Effects of variety and repeated in-home consumption on product acceptance. Appetite. 2000; 35:113-119. [PubMed: 10986104]

Zheng HY, Berthoud HR. Eating for pleasure or calories. Current Opinion in Pharmacology. 2007; 7(6):607-612. [PubMed: 18037344] 


\section{Table 1}

Characteristics of participants who rated images for food appeal. ${ }^{a}$

\begin{tabular}{lccc}
\hline & Men $(\mathbf{n}=\mathbf{5 6})$ & Women $(\mathbf{n}=\mathbf{7 3})$ & Total $(\mathbf{n}=\mathbf{1 2 9})$ \\
\hline Age (years) & $34.5 \pm 11.2$ & $33.3 \pm 11.3$ & $33.8 \pm 11.5$ \\
BMI $\left(\mathrm{kg} / \mathrm{m}^{2}\right)$ & $26.0 \pm 5.5$ & $25.7 \pm 7.8$ & $25.9 \pm 6.8$ \\
Hunger (Range, $0-100)$ & $35.0 \pm 23.3^{*}$ & $25.2 \pm 21.3$ & $29.5 \pm 22.6$ \\
Education (years) & $16.1 \pm 1.2$ & $15.5 \pm 1.7$ & $15.7 \pm 1.5$ \\
Dietary restraint ${ }^{b}$ & $8.1 \pm 4.5$ & $9.0 \pm 4.5$ & $8.6 \pm 4.5$ \\
\hline${ }_{\text {Mean } \pm \text { SD. }}$ & \\
$b_{\text {Three Factor Eating Questionnaire (Stunkard \& Messick, 1985). }}$ \\
* Indicates significant difference between men and women, independent samples $t$-test $(p<.05)$.
\end{tabular}




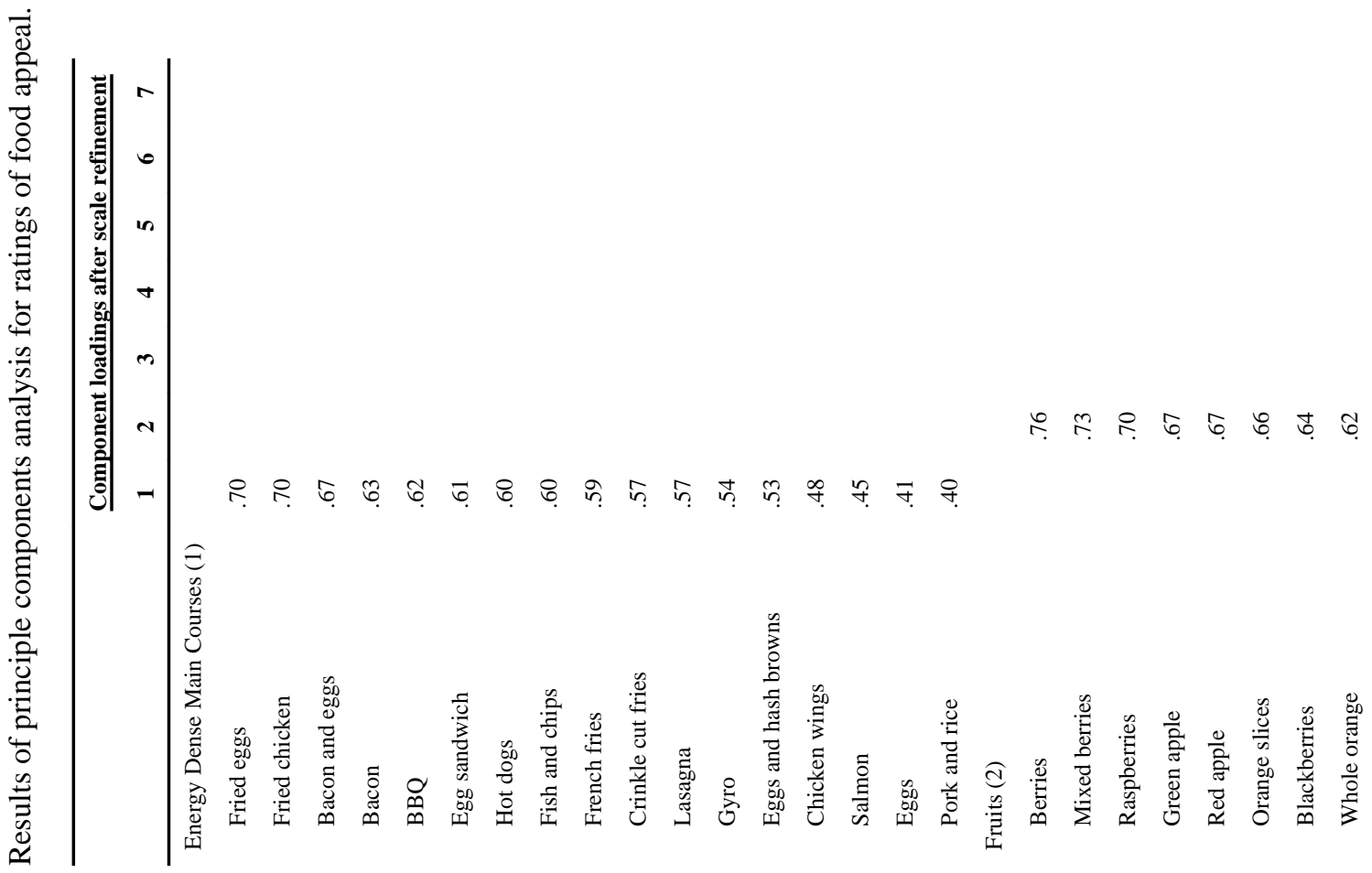




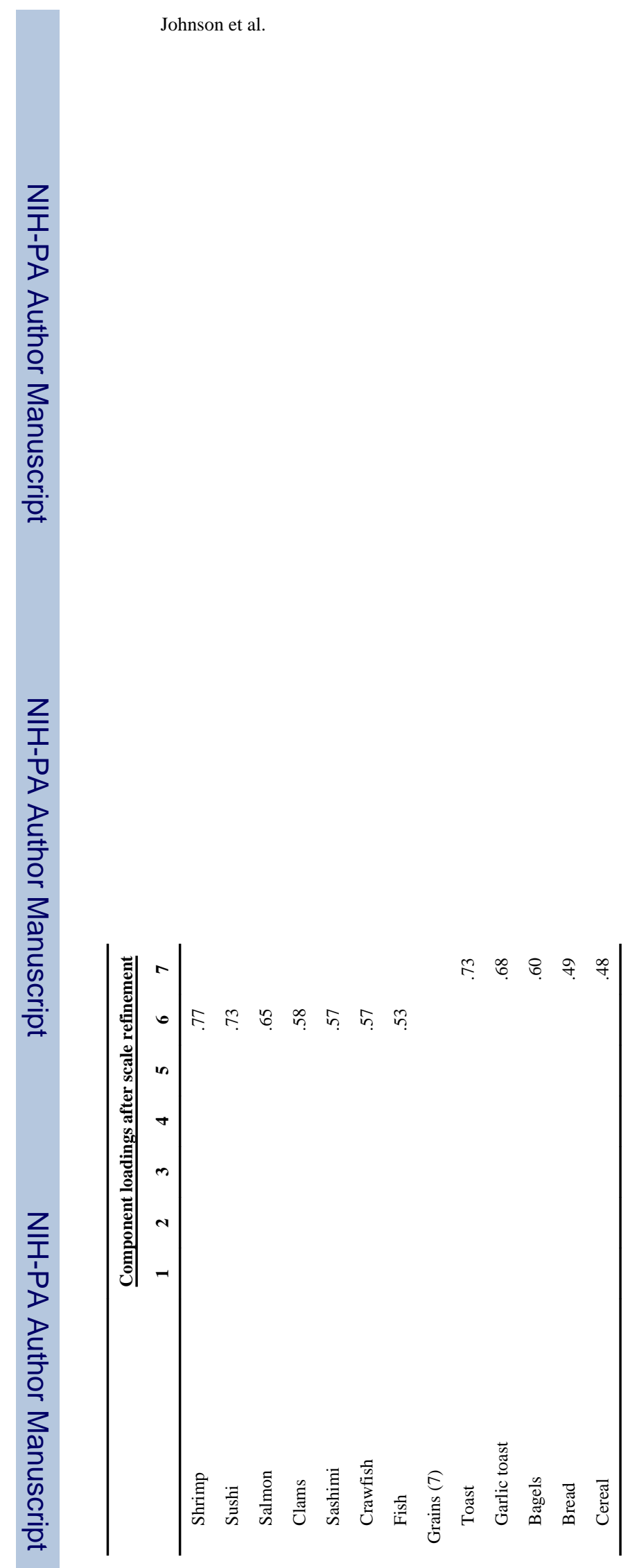

Page 19 


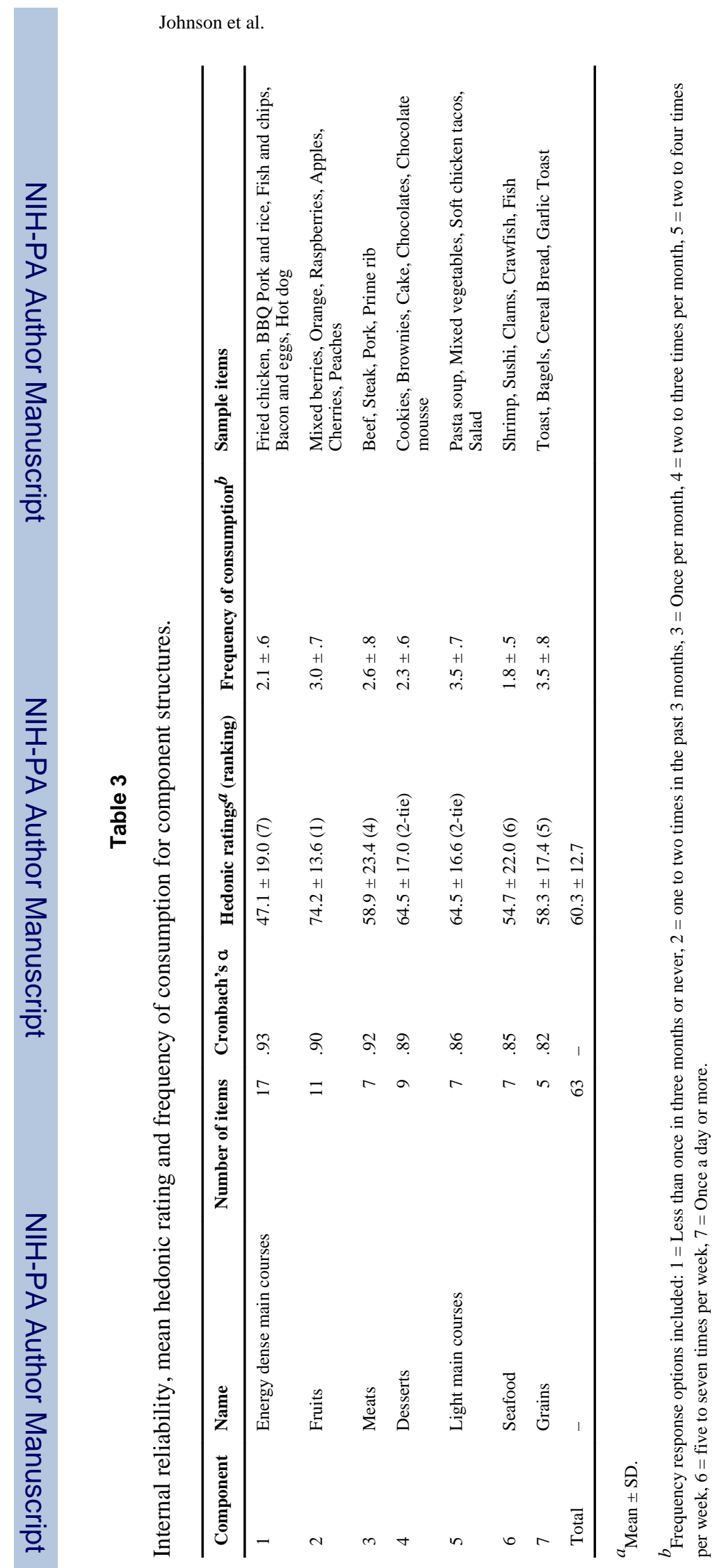

Appetite. Author manuscript; available in PMC 2014 August 01. 


\section{Table 4}

Percent agreement of food images between traditional food groups and loadings on food components from the Principle Components Analysis (PCA). ${ }^{a, b}$

\begin{tabular}{llc}
\hline Traditional food group $\boldsymbol{a , c}$ (number of items) & PCA factor name (number of items) & Percent agreement $\boldsymbol{b , \boldsymbol { d }}$ \\
\hline Mixed dishes (28) & Energy Dense Main Courses (17) & $47 \%(8 / 17)$ \\
Fruit (18) & Fruits (11) & $100 \%(11 / 11)$ \\
Protein (24) & Meats (7) & $100 \%(7 / 7)$ \\
Discretionary foods (21) & Desserts (9) & $89 \%(8 / 9)$ \\
Vegetables (15) & Light Main Courses (7) & $57 \%(4 / 7)$ \\
Protein (24) & Seafood (7) & $71 \%(5 / 7)$ \\
Grains (16) & Grains (5) & $100 \%(5 / 5)$ \\
\hline
\end{tabular}

${ }^{a}$ A priori traditional food groups as presented in Burger et al. (2011).

${ }^{b}$ Percent agreement analyses included only those items that adequately loaded onto a factor. Sixty-six items were excluded as a result of the PCA.

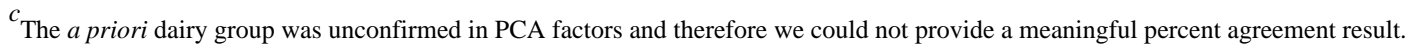

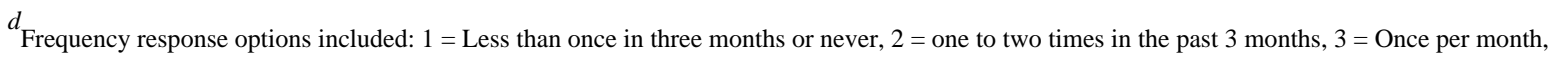
$4=$ two to three times per month, $5=$ two to four times per week, $6=$ five to seven times per week, $7=$ Once a day or more. 


$$
\begin{aligned}
& \text { ลิ } \\
& \text { II }
\end{aligned}
$$

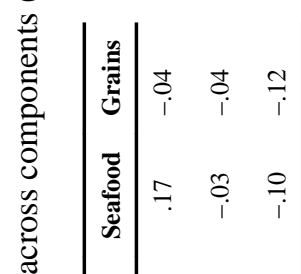

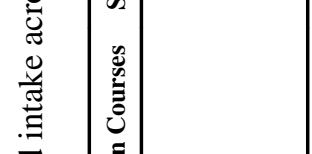

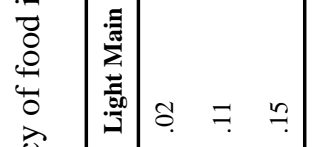

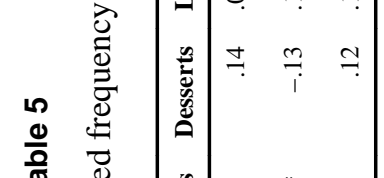

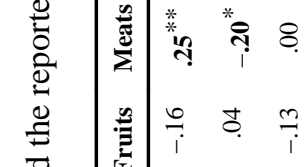

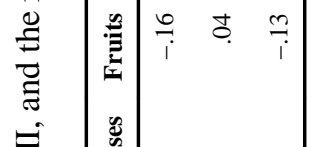

$$
\begin{aligned}
& \sum_{m}
\end{aligned}
$$

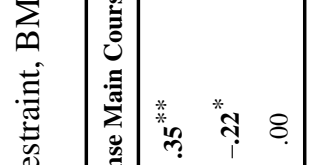

